\title{
Learning as a Systemic Activity
}

\author{
Olga Pinchuk, Oleksandr Burov, Svitlana Lytvynova ${ }^{1}$ \\ ${ }^{1}$ Institute of Information Technologies and Learning Tools \\ of National Academy of Educational Sciences of Ukraine, \\ 9 M. Berlyns'koho st., 04060, Kyiv, Ukraine \\ opinchuk100@gmail.com, ayb@iitlt.gov.ua, s.h.lytvynova@gmail.com
}

\begin{abstract}
This paper describes theory (systemic structural model) of learning activity, as well as demonstrates (on experimental data) changes in intelligence structure on "micro-age" intervals. They are compared specific changes of intelligence structure of pupils of grades 10-11 and students of the 1st year of Kiev University of Economics, masters of psychophysiology, physicians (psychophysiologists), and patent experts. Principles of ergonomic design for learning workplace are proposed.
\end{abstract}

Keywords: Human Factors · Functional System of Activity · Intellect structure $\cdot$ Learning

\section{$1 \quad$ Introduction}

To date, it is recognized that we live in the knowledge society and a human individual cognitive and creative abilities become crucial for the humanity development [1]. Children of the twenty-first century were born, grow, study, master the profession live and work in the information age, where the surrounding world is increasingly losing the features of the material world and turning into the world of information and knowledge [2]. Correspondingly, the means of training are changing in time[3], the synthetic part of the educational process [4] replaces increasingly the interaction between "human-human" and "human-material carrier of information".

Throughout history, advances in information and communication technologies, energy and transport technologies, biotechnology and natural sciences, agriculture and industry, military technology, as well as in other areas of science and technology play an important role in the process of radical changes in how people deal with their affairs. Today's society lives de facto and de jure in the information age, as evidenced by a number of international instruments adopted at international forums and materials from the World Economic Forum in Davos (2017-2019). As a result, digital space is increasingly embracing all areas of our lives, first of all, education and training that are the basis of a human capital.

Modern education needs to be more and more individual-oriented, securing individual psychophysiological abilities and development. Effectiveness of the collaboration of humans and technical, didactic and organizational subsystems could be achieved, if learning activity is considered and designed as activity of a system which structure includes a human (learner), learning environment and learning tools/means. Each from these three components has its own structure and functions, and general 
system performance can be described in terms of the systemic-structural activity theory [5].

Purpose. To analyze learning activity from point view of systemic organization including information and cognitive components.

\section{Discussion of results}

Three things are needed to succeed in responding to quick changes in life and technology: we must notice and recognize a certain change; we must understand the consequences of this change; we need to make timely and effective decisions about it; it must be understood that not only new means and opportunities arise, but a digital transformation of the human life and human activity that was actively discussed at the Davos Forum in 2019. First of all, it concerns new technologies that accompany us in all areas of our lives and activities - information and communication technologies (ICTs) - and also directly affect not only our present, but also the future.

The transformation of the role of information networks and their place in human life has led to shift the emphasis of network designers towards the anthropocentric nature of their construction and existence, the emergence of the need to apply the concept of not only "integration of networks", but also the concept of "integrated human-centric network." A new type of integrated network becomes not a passive element of innovative processes, but is active as it changes significantly the character of contemporary creation, which becomes a "currency" with its laws of formation, development, circulation and the need for protection. All these types of human activities are related to the creation of new ideas, new intellectual products, which are not in the process of creation strictly localized in the place of their creation, that is relatively open and not protected from external expansion.

The experience of ergonomic science makes it possible to optimize the interaction of a person with the environment and means of activity, including in the information environment. Ergonomics as a scientific and practical discipline is aimed at ensuring high efficiency of human activity, its safety and comfort. One of the ways to achieve such a triple task is to create an effective psycho-physiological support for the ability to work in the process of both work and learning. Macroergonomic approach involves the systematic solution of issues of analysis of a certain type of activity, designing its optimal conditions, selecting and adapting a person to this activity, solving technical and organizational issues of providing effective and safe education and labor.

Activity is a main substance of our everyday life. But its scopes become relative, not clearly defined because of:

- changes in our goals and needs (earning, cognition, leisure),

- tools and facilities (electronic equipment in workplace, in office, at home),

- workplace design and construction (more ergonomic and comfortable),

- location (outsourcing job),

- $\quad$ increasing of mental component work (in contrast with physical one),

- day time span of the same or similar type of activity.

Especially it is actual for education, because today's learning can be carried out anywhere and at any time thanks to different gadgets including mobile ones. From the other side, modern jobs need skills not so specialized, as general. In other words, Re- 
quirements for a highly qualified specialist are not of narrow profile, but of a systemic nature. Accordingly, education process should form a specialist from systemic positions: vocational, behavioral, communicative, personal and social. Environment of a human activity should be evaluated as natural (physical, biological), informational, organizational, technical and social. In other words, education is in focus of ergonomics, which combine a human, tools of activity and environment by their interaction to satisfy efficiency of the general system, safety and comfort of activity (Fig.1).

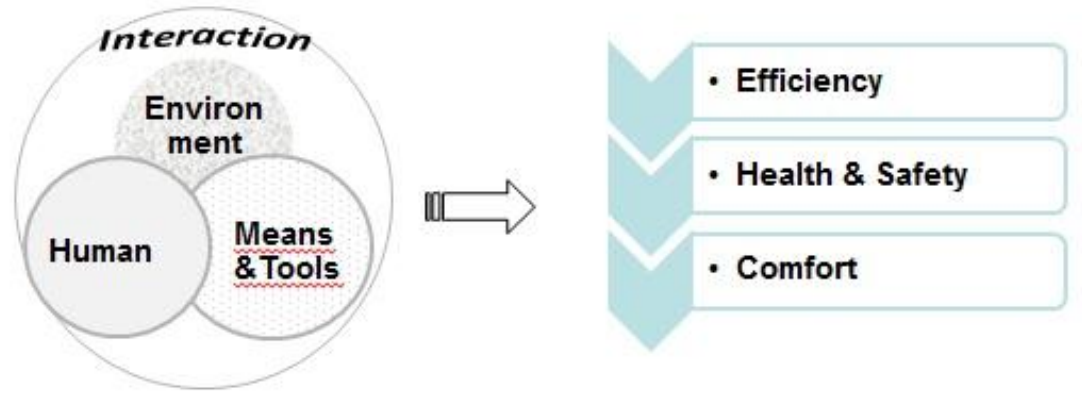

Fig.1. Ergonomics objects and goal.

Learning is a system of activity that forms a future specialist in his/her interaction with external environment and internal state.

Models and appropriate ICT tools were developed for the system "Learnertechnology/tools-environment" (SLTE) accounting a learner psychophysiological individual features and stages of learning [6]. Functional system of cognitive activity (FSCA) in digital environment has been developed by authors as a refinement of the previous general functional system of activity after K.Anokhin [7]. In general case, the conceptual model is considered as an information stratum of professional activity, and physiological chain ,afferent inputs - activity acceptor - physiological control effectors - act" is an energetic stratum in this context (Fig.2). According to authors view, the goal of professional learning and training is to form the conceptual model of activity of the particular type, carrying out particular tasks. The FSCA was proposed as a structural functional system representing psychophysiological model of cognitive activity, and as a hyper-complex dynamic (HCD) system. Considering student's ability to learn (SAS) as a three-level closed hyper-complex dynamic system, in which factors of influence on the efficiency of SLTE are the elements of the HCD that interact with each other, "the general suitability for the profession can be represented as the first level HCD, micro-age - as the second level HCD, current - as HCD of the third level".

In addition, the authors propose to single out an independent circuit "cognitive contour" for FSCA in the SLTE, because learning activity can occur without external object, f.e., in VR/AR environment [8], in adaptive learning systems [9]. In the digital world and synthetic learning the external object may not exist. "Instead of it, the virtual object can appear ("cogni object") that is produced by the virtual act program and can be not a result of training and experience, existing in time of the particular activity (f.e., during the game). This object and interaction with it can be created by sensors (information for them is produced by artificial system, virtual one, simulating real 
world) and the act acceptor compares virtual result with virtual sensors signals, creating the cognitive model of the synthetic object" [6]. In such a case, an illusion of the object as well as knowledge regards it can appear. But it should be specified that didactics of teaching process can influence to both "Act acceptor" and "Object" in this model.

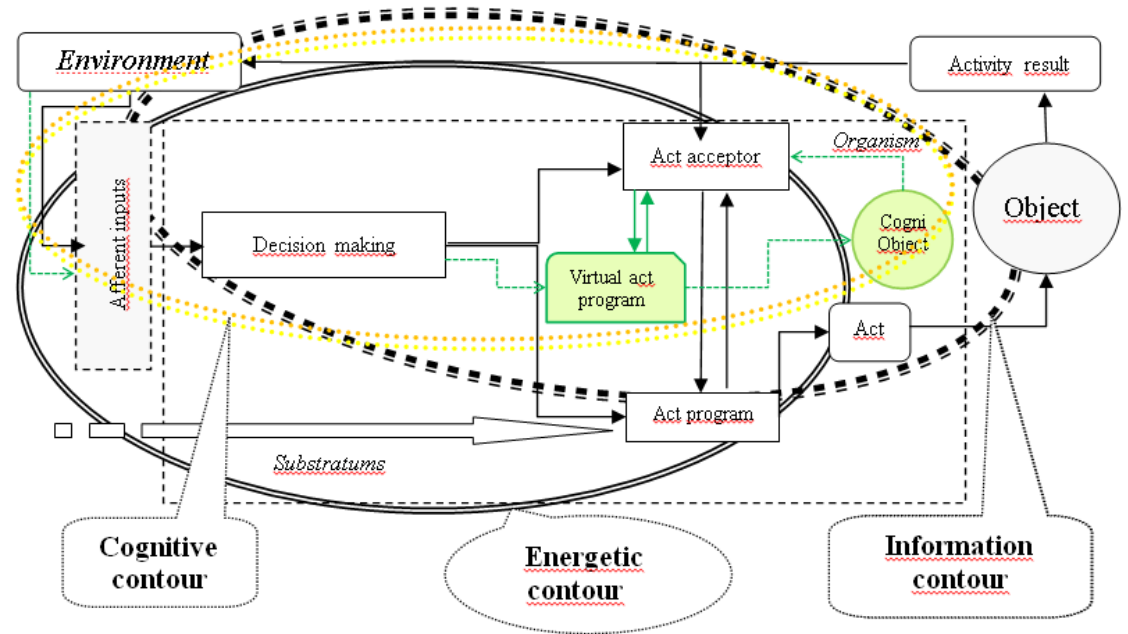

Fig. 2. Theoretical scheme of the functional system of learning activity, where regulation was divided into two contours - information and energetic ones. The third (cognitive) contour is associated with the "internal" activity (cited by [6])

This model of the learning activity helps to imagine how the system of educational activities is formed.

At the same time, we would like to articulate two sides and three levels of psychophysiological maintenance of learning activity (Fig.3).

Two sides are: (1) internal, described above, that is associated with physiological maintenance and functional state of the learner in a particular time; (2) external, behavior, that is associated with his/her performance in learning.

Three levels of psychophysiological maintenance: (a) principal ability of learner to learn in general or to study a specific profession; (b) psychophysiological and cognitive changes over a learning time; (c) current state of the learner and his/her ability/readiness to accept effectively the proposed kind of learning tasks (take lectures, laboratory exercises, tests performance etc.). This could be especially important for individual-oriented education.

This model explains relationship between external and internal organization of e learner features and parameters that could be measured to assess his/her learning performance system and its success or degradation. Existed theoretical basis did not allow to answer questions What? Where? Why ? When ? In what way? should be measure to provide a high accuracy of the human performance prediction. But the model could help us. 


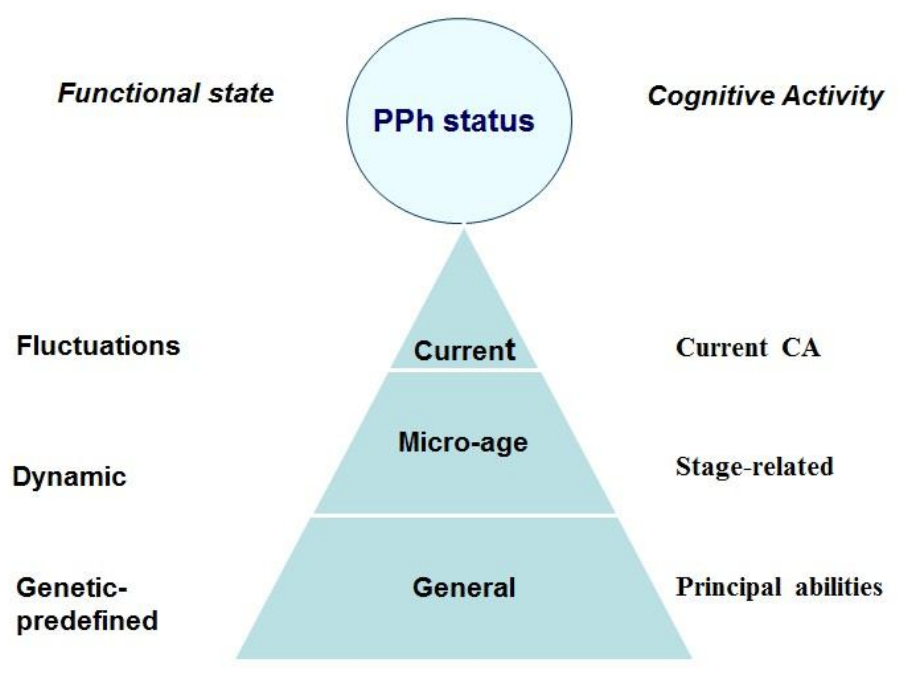

Fig. 3. Sides and levels of psychophysiological maintenance of learning activity

A human (learner) activity is accompanied by creation and maintenance of functional system that:

- activates dominant brain structures,

- activate corresponding activity of one or another physiological system,

- is quite stable for particular type of the human activity.

Actual FSA depends on a particular type of learning activity and can activate different mechanisms of performance. Depending on this, a student can be considered as an operator-watcher, operator-researcher or operator- manipulator, and his/her activity can be measured and assessed from viewpoint of ergodynamics.

Human lives and acts in digital space (DS). Young children born, grow, learn and will work with gadgets being linked in networks as a natural environment. Their lives are influenced by DS with old and new hazards, where their performance depends on more cognitive factors (interface, content, models of behavior) and is a result of safety, efficiency, health (HF/E domain). They are discussed challenges evoked by life\&activity (L\&A) in DS in relation to influenced factors, ways of their avoiding and appropriate tools. Analysis is based on experience of HF/E findings for adults (emergent and military operators) and features of cognitive abilities of high school students. According to research data regards giftedness and its relationship with intellect structure, it is recognized that intellect does not explain the whole giftedness and general abilities of people, but is a background of any ability and its structure can be considered as the systemic characteristic of a human mental performance, as well as professional suitability.

In order to clarify these peculiarities of modern education, the research of common and/or special features of the structure of intelligence among representatives of different age groups (correspondingly, by education and profession) was carried out of groups of people motivated by intellectual activities. 
Volunteers participated in experimental studies:

36 pupils of grades 10-11 and students of the 1st year of Kiev University of Economics - mean age 16.7 year old,

27 military masters of psychophysiology - mean age 23.2 year olds,

28 physicians (psychophysiologists) - mean age 32.1 year old,

42 patent experts - mean age 41.1 year old.

The analysis of the results was carried out only for those subjects who performed all tests with a given level of speed and reliability, the intelligence structure after R. Amthauer test was used. Structural components of the intellect are assesse:

1. LS - logical selection - tests the feeling of language, the ability to formulate judgments.

2. GE - definition of common features - tests abstract ability.

3. AN - definition of similarity - tests combinatorial abilities, dynamic thinking.

4. RA - computational and mathematical - tests the ability to solve computational problems of a practical nature.

5. ZR - detection of regularities - tests logical and mathematical thinking.

6 . Fs - the choice of figures - tests spatial thinking in terms of geometric combinations on a plane in the formation of an integer shape of its fragments.

7. Wv - task with cubes - tests spatial thinking.

8. Me - memory, attention - tests volume and concentration of attention, as well as operational memory.

Results of comparative analysis have demonstrated that the verbal intellect (VI) is higher than non-verbal one (NI) for all groups of subjects (Fig.4).

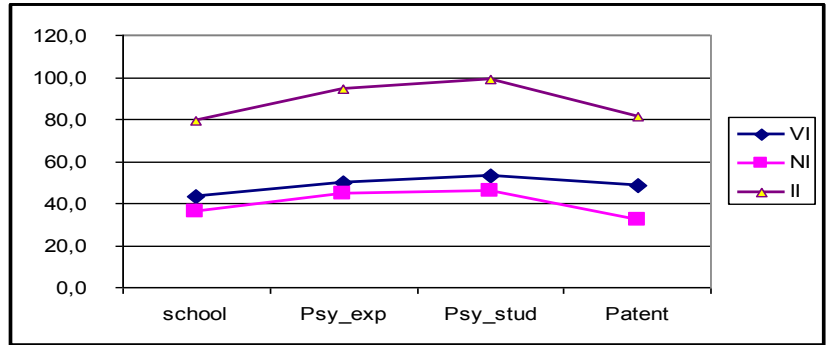

Fig. 4. Verbal and non-verbal intellect of subjects

But the intellect structure differed in those groups (Fig. 5).

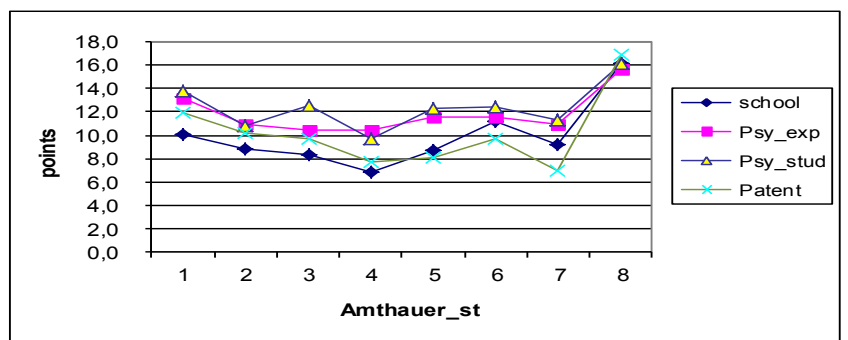

Fig. 5. Intellect structure of the same groups' subjects 
As it was expected to some extent, verbal components of the intellect was lowest in schoolchildren, but special thinking and memory were higher than in the patent experts' group. In general, one can make a decision that any type of vocational learning develops intellect as a general thinking system.

Possible question is: what are requirements for the learning in ergonomics of the digital age [10]? What principles of the information and communication technology' system for learning are?

We propose principles of ergonomic design for learning workplace as follows:

1. Subject-oriented design of workplace.

2. Context of used approach.

3. Adequate learning/working tools and means.

4. User-friendly learning/working environment.

5. Developing activity.

6. Effectiveness/reliability as a goal of learning/working process.

7. Safety of user 's mental and physical health.

8. Comfort of user's learning/working process.

9. User resilience under possible negative impact from the network and ICT in general.

In addition, we have to articulate the necessity to take into account that digital life and activity gives new opportunities for people and new problems for $\mathrm{HF} /$ Ergonomists, lists of draw-backs and risks can and will be extended according to new experience to use eWorld, because in network-oriented space, where "node (human/other agent) - interface - link - network" is a space of information existence [11]. As a result, nea features of ergonomics/human factors appear: in "hard" (material) workspace human-produced, "pushed-out", result can be always identified (localized) in space and/or in time, but result of human activity in "soft" SLTE or human-aided agent (information) can be not always localized both in time and space.

Such an environment could produce new hazards from the domain of cybersecurity [12], that faces new features of the learning as a system activity.

\section{Conlusion}

This paper describes theory (systemic structural model) of learning activity, as well as demonstrates (on experimental data) changes in intelligence structure on "micro-age" intervals. They are compared specific changes of intelligence structure of pupils of grades 10-11 and students of the 1st year of Kiev University of Economics, masters of psychophysiology, physicians (psychophysiologists), and patent experts.

Understanding of these changes can be used for learning improvement using basic points of SLTE regards the interrelationship between the structure and self-regulation of learning activity.

Acknowledgments. This research has been supported by the Institute of Information Technologies of the National Academy of Pedagogic Science. 


\section{References}

1. Bykov V.Ju.: Innovative development of society and modern technologies of open education // Problemy ta perspektyvy formuvannja nacionaljnoji ghumanitarno-tekhnichnoji elity: P78 zb. nauk. pracj / za red.. L.L. Tovazhnjansjkogho, O.Gh. Romanovsjkogho. Vyp. 23-24 (27-28), Kharkiv: NTU "KhPI", 24--49 (2009)

2. Gavan Naden: The great learning curve: how to improve your study habits. The Guardian, 22 Mar 2018. Access: https://www.theguardian.com/education/2018/mar/22/the-greatlearning-curve-how-to-improve-your-study-habits (2018)

3. Encyclopedia of the Sciences of Learning. Seel, Norbert M., Ed. Springer US, 2012 (in English)

4. Pinchuk O., Lyvynova S., Burov O.: Synthetic educational environment - a footpace to new education / O. Pinchuk, S. Lyvynova, O. Burov // Informacijni tekhnologhiji i zasoby navchannja: elektronne naukove fakhove vydannja, V.60, № 4, 28--45 (2017) in Ukrainian

5. Bedny, G. Z., \& Karwowski, W.: A Systemic-Structural Activity Approach to the Design of Human-Computer Interaction Tasks. International Journal of Human-Computer Interaction, 16(2), 235-260 (2003)

6. Spirin O., Burov O.: Models and Applied Tools for Prediction of Student Ability to Effective Learning, In: 14th International Conference on ICT in Education, Research and Industrial Applications. Integration, Harmonization and Knowledge Transfer, Vol-2104, pp. 404-411 (2018).

7. Anokhin, P.K.: Principal questions of the general theory of functional system. Principles of the system organization of function / P. K. Anokhin. Moscow: Science, 5-61 (1973)

8. Alexander T., Ripkens A., Westhoven M., Kleiber M., Pfendler C.: Virtual TeleCooperation: Applying AR and VR for Cooperative Tele-Maintenance and Advanced Distance Learning. In: Andre T. (eds) Advances in Human Factors in Training, Education, and Learning Sciences. AHFE 2017. Advances in Intelligent Systems and Computing, vol 596. Springer, Cham (2018)

9. Scerbo M. W., Freeman F. G., Mikulka P. J.: A brain-based system for adaptive automation. Theor. Issues Ergon. Sci. 4, 200-219, 10.1080/1463922021000020891 (2003)

10. Wilson John R., Carayon Pascale: Systems ergonomics: Looking into the future - Editorial for special issue on systems ergonomics/human factors. Applied Ergonomics. Volume 45, Issue 1, 3-4, (2014).

11. O. Burov: Virtual Life and Activity: New Challenges for Human Factors/Ergonomics. In: Symp. Beyond Time and Space STO-MP-HFM-231, STO NATO, pp. 8-1..8-8 (2014).

12. Burov O.Ju.: Educational Networking: Human View to Cyber Defense. Institute of Information Technologies and Learning Tools 52, 144--156 (2016) 